\title{
Mandibular Canal Duplication Prevalence, Digital Panoramic Radiography Analysis
}

\author{
Prevalencia de las Bifurcaciones del Canal Mandibular, \\ Análisis en Radiografías Panorámicas Digitales
}

Juan Schilling Lara*; Alejandro Schilling Quezada* \& Jaime San Pedro Valenzuela*

SCHILLING, L. J.; SCHILLING, Q. A. \& SAN PEDRO, V. J. Prevalencia de las bifurcaciones del canal mandibular, análisis en radiografias panoramicas digitales. Int. J. Odontostomat., 4(3):207-213, 2010.

\begin{abstract}
The increase in the number of surgical procedures in the mandibular region requires a new perspective into anatomical landmarks such as the mandibular canal and its imagenological aspect. The present study aimed to determine the prevalence of the alterations in the number of mandibular canals in digital panoramic images obtained from patients of a private radiological center of the Maule region. The study period was from March to December 2008 . A total of 350 panoramic digital X-ray images were analyzed by examining them for hemi-mandibles $(n=700)$ and quantifying the alterations of the number of mandibular canal. There were 35 cases of bifurcations to the mandibular canal, corresponding to $5 \%$ of the sample in the study. The obtained information indicates a major prevalence described by the literature, which reinforces the need of a larger study of the radiographic images of the mandibular canal, considering the difficult managing of a surgical complication on this anatomical structure.
\end{abstract}

KEY WORDS: mandibular canal, digital panoramic radiography, inferior alveolar nerve.

\section{INTRODUCTION}

With the development of the oral implants and the growth in the number of surgical procedures carried out in the mandible, the study of the mandibular canal has become even more important; the literature shows variations in the presentation, which are observed in the image projected in the surface as much as in the disposition of the internal structures (Gowgiel, 1992; Flygare, 2008).

The importance of determining the prevalence of the alterations of the number and disposition of the mandibular canal can be seen in its clinical and surgical implications, which can range from difficulties in the anesthetic technique for the inferior alveolar nerve block (Lew, 2006) to serious surgical complications in procedures such as the location of oral implants, reduction of mandibular fractures, or extraction of third molars (Claeys, 2005).

The radiographic image of the mandibular canal appears as a radiolucid band delimited by two radiopaque lines (Worth, 1963). Nevertheless, many anatomical and pathological variations can alter the common pattern of the mandibular canal determining different radiographic images (Farman, 1977; Denissen, 1984).

Carter and Keen (1971) confirm the affirmations of Olivier (1927) who found, in $60 \%$ of the dissected mandibles, a mandibular canal that contained the totality of the Inferior alveolar nerve, whereas in the remaining $40 \%$, the branches of the nerve were separating, and a clearly definite channel was not observed. There are rare supplementary mandibular canals sufficiently long to be able to observe them in panoramic X-ray images, but occasionally, they appear, more commonly, as duplicated mandibular canal with a common mandibular foramen and less frequent originating in separated mandibular foramen. These duplicated canals are only in $0.5 \%$ to $1 \%$ of the adult population studied. These duplicated canals are denominated, on occasion, as bifid mandibular canals; some of these supposed bifid canals are only the projection of artifacts, which has been proven in the anatomical dissection as in CT scans. 
Chávez-Lomeli et al. (1996) suggested that during the embryonic development, three canals and nerves fuse to form a unique nerve and mandibular canal; a lack of merger of these channels can explain the presence of multiple channels in some individuals. In prenatal studies of the development of the human dentition, they suggest that the tooth development correlates with the maturation of the surrounding bone (Kjaer, 1988). These three different components of the inferior alveolar neurovascular bundle indicate the existence of three different zones of development in the mandibular dentition. These zones are innervated for different nerve branches with different origins.

In some cases, there exists a poor definition of the image of the mandibular canal. The possible observation of an eventual bifurcation or duplication is extremely difficult. Wadu et al. (1997) confirmed by dissections that the radiographic appearance of the edges of the mandibular canal form different patterns, ranging from alternating bands of radiopacity and radiolucency to continuous radiopaque lines, related to the number and distribution of the osseous trabeculae around the mandibular canal. In all the individuals analyzed, traces of the mandibular canal could be observed. If the narrow spaces are different in size and distributed at random, it could show an erratic and inconsistent margin on the Xray image; when the osseous trabecula is small and uniform, the radiographic image is a radiopaque margin in the mandibular canal. As the trabecula becomes bigger and its distributive pattern more random, the radiographic appearance can suggest a cribriform pattern, or it might have no identifiable limits. In addition, it is necessary to consider that the absence of the mandibular canal image can be due to not only the type of trabeculae but also a minor caliber of this one; this idea can find support in the study published by Carter and Keen where, on the analysis of dissected jaws, they observed that nervous and vascular elements entering the mandibular osseous tissue could be traced up to neurovascular bundles of masticatory muscles.

In the study published by Polland et al. (2001), the anatomy of the mandibular canal is described, in panoramic X-ray images of edentulous jaws, as a radiolucent of poorly defined margins representing the mandibular foramen, a mental foramen difficult to observe, and the mandibular canal is observed as a radiolucent dark ribbon between two white lines in some cases and with poorly defined edges in others; in all the cases, the canal was less defined in the mandibular body than in the mandibular ramus, losing lost the definition as it advances toward the mental foramen.

\section{Classifications}

Carter \& Keen examined human dissected jaws and described three types of dispositions of the mandibular canal, in relation to its location with regard to the basilary edge:

Type I: the inferior alveolar nerve was a single large structure lying in a bony canal.

Type II: the nerve is situated substantially in the lower part of the mandible.

Type III: the inferior alveolar nerve gives off two large branches posteriorly, which could be regarded as equivalent to an alveolar branch.

Langlais et al. (1985) published a classification of the mandibular canal duplication in relation to the anatomical location and to his configuration:

Type I: represents unilateral or bilateral bifid canals that extend to the mandibular third molar area or the immediate surrounding area.

Type II: includes unilateral or bilateral bifid canals that rejoin within the mandibular ramus.

Type III: is a combination of types I and II.

Type IV: two canals, each of which originates from a separate mandibular foramen, join to form one larger canal.

Langlais et al. also stated that normal canals or bifid canals may have additional smaller accessory canals.

Sanchis et al. (2003) examined 2012 panoramic X-ray images (1276 women and 736 men) looking for suggestive images of a duplicated unilateral or bilateral mandibular canal, with only 7 cases corresponding to $0.35 \%$ of the sample. All these cases appeared in women, and in three of the cases, a computer tomography (CT) was realized to confirm the diagnosis of double canal. In two of the patients who underwent $\mathrm{CT}$, the double canal was unilateral in one and bilateral in the other; in the case of the double bilateral canal, it was not possible to confirm its presence with the tomography. On the other hand, in both cases of double unilateral channels, it was confirmed successfully by the CT.

The present study aimed to determine the prevalence of mandibular canal duplications in panoramic images of the period from March to December, 2008, obtained from patients of a private radiological center of the Maule region. 


\section{MATERIAL AND METHOD}

A total of 350 panoramic digital X-ray images were analyzed, with a sample of 700 images of hemimandibles. These images were obtained from consecutive cases from a radiographic private center and covered the period March to December 2008; the images were obtained from patients with permanent dentition that fulfilled the eligibility criteria.

The mean age of the sample was 30.4 years (Sd 16,71 years). As for the distribution for sex, $58 \%$ of the sample $(n=406)$ were female and $42 \%(n=$ 294) were male.

Excluded are the patient images presenting deciduous dentition, malformations in body or mandibular ramus, cystic or tumor processes of great size, given possibility of altering the radiographic image and therefore the information on the possible bifurcations of the mandibular canal.

As for the radiographic images, panoramic $X$ ray images were taken with Siemens Sirona Orthophos XG5 equipment, and the images analyzed in TIFF format (Tagged Image File Format) on a monitor flat screen TFT-LCD (Thin Film Transistor-Liquid Crystal Display) with a resolution of $1280 \times 800$ pixels; these images were examined with variations of density and contrast and the application of the filter brightness plus, with Sidexis next generation v. 1.51 software.

For the interpretation of the X-ray images these were projected on a monitor TFT flat screen of 17 inches with black screen background in an environment of total darkness. The images were checked by a maxillofacial radiologist, analyzing every hemi-mandible separately, being able to use the zoom tool of the software. Thus defining the presence of the mandibular canal, or bifid unilateral or bilateral canals. In case of appearing bifid unilateral or bilateral channels they were grouped according to the classification of Langlais et al.

Statistical analysis was performed using the program Statistical Package for the Social Sciences (SPSS) v. 14.0.

\section{RESULTS}

In Table I, it is possible to observe the distribution of the mandibular canal duplications of the analyzed jaws, in 35 hemi-mandibles, of the 700 observed, with a prevalence of $5 \%$ of the sample, it was possible to estimate some degree of bifurcation of the mandibular canal.

In the cases of bifurcated canals, 35 cases corresponded to $30 \mathrm{X}$-ray images, where the canals appeared of unilateral form in $25 \mathrm{X}$-ray images and the bifurcated cases were bilateral in $5 \mathrm{X}$-ray images.

Of the 25 cases of duplicated canals, 21 corresponded to type I of the classification of Langlais et al. (Fig.1) (it represents duplicated mandibular canals unilateral or bilateral that spread to the area of the third molar or to the immediately adjacent area).

Of 25 unilateral cases 4 presented characteristics similar to the type II of the classification of Langlais et al. (includes unilateral or bilateral bifid canals that rejoin within the ramus of the mandible) (Fig. 2). In 5 cases of bilateral mandibular canal duplications, 3 corresponded to the type I of the classification of Langlais et al. and 2 to the type II of the classification.

\section{DISCUSSION}

The presence of a bifid or duplicated mandibular canal must be considered at the time of realizing any surgical procedure in the area of the mandibular ramus and the mandibular body, such as dental extractions, reduction of fractures, placement or removal of implants, including root canal treatment. In these cases there is possibility of injuring the inferior alveolar nerve, which importance increases upon checking the study published by Sato et al. (2005) which demonstrates by macroscopic dissection and CT scans, the lower artery, vein and alveolar nerve (principal trunks) were in close contact to the apexes of the second molar.

Tabla I. Frecuency distribution of the mandibular canal duplications.

\begin{tabular}{rcccc}
\hline & Frequenc & Percent & Valid & Cumulative \\
\hline Absent & 665 & 95.0 & 95.0 & 95.0 \\
Present & 35 & 5.0 & 5.0 & 100.0 \\
Total & 700 & 100.0 & 100.0 & \\
\hline
\end{tabular}




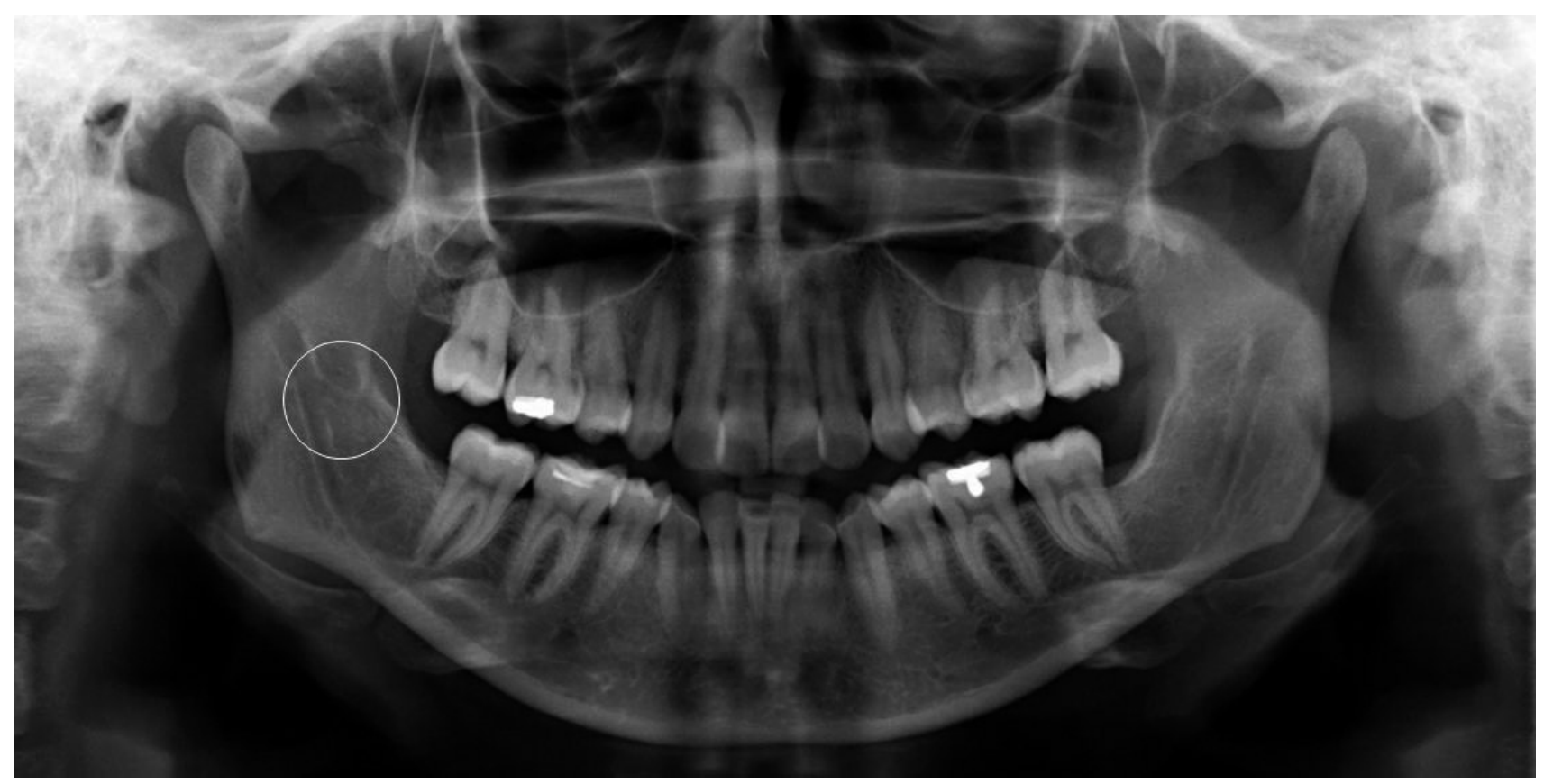

Fig. 1. The circle in the left shows a unilateral bifid mandibular canal that extends to the right third molar area.

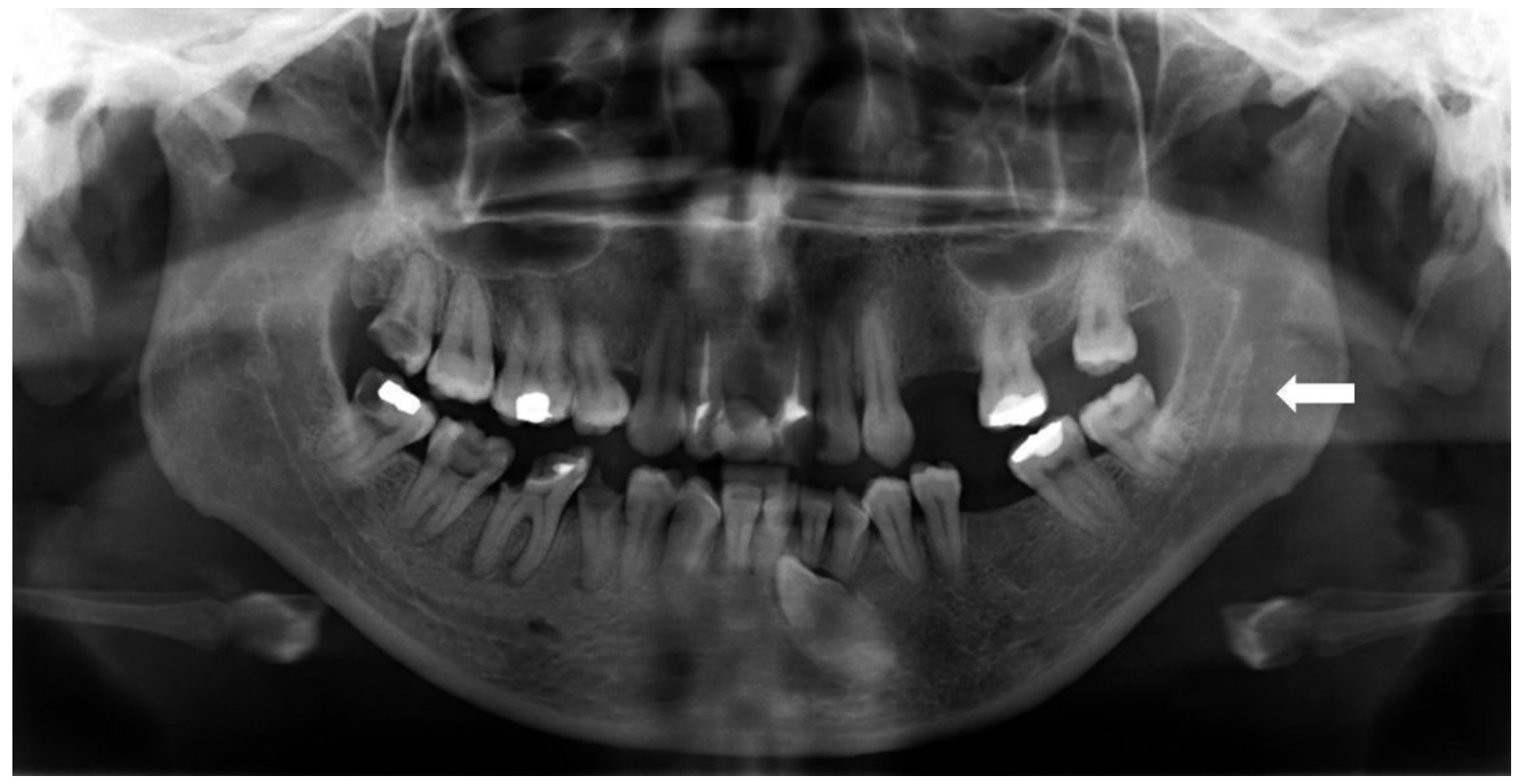

Fig. 2. The arrow indicates a unilateral bifid canal that rejoins within the mandibular ramus (type II of the Langlais et al. classification system).

The number of duplicated mandibular canal cases was higher than that reported in other studies, as Sanchis et al., where there was a prevalence of only $0.35 \%$ of mandibular canal duplications, in contrast to $5 \%$ found in the present study. This could be due to the better quality of images obtained by current digital equipment. It is necessary to consider that the prevalence in the present study was interpreted as a sign of bifurcation, the unilateral or bilateral observed cortical that emerges from the loss of continuity in the upper cortical of the mandibular canal (Fig. 3). 


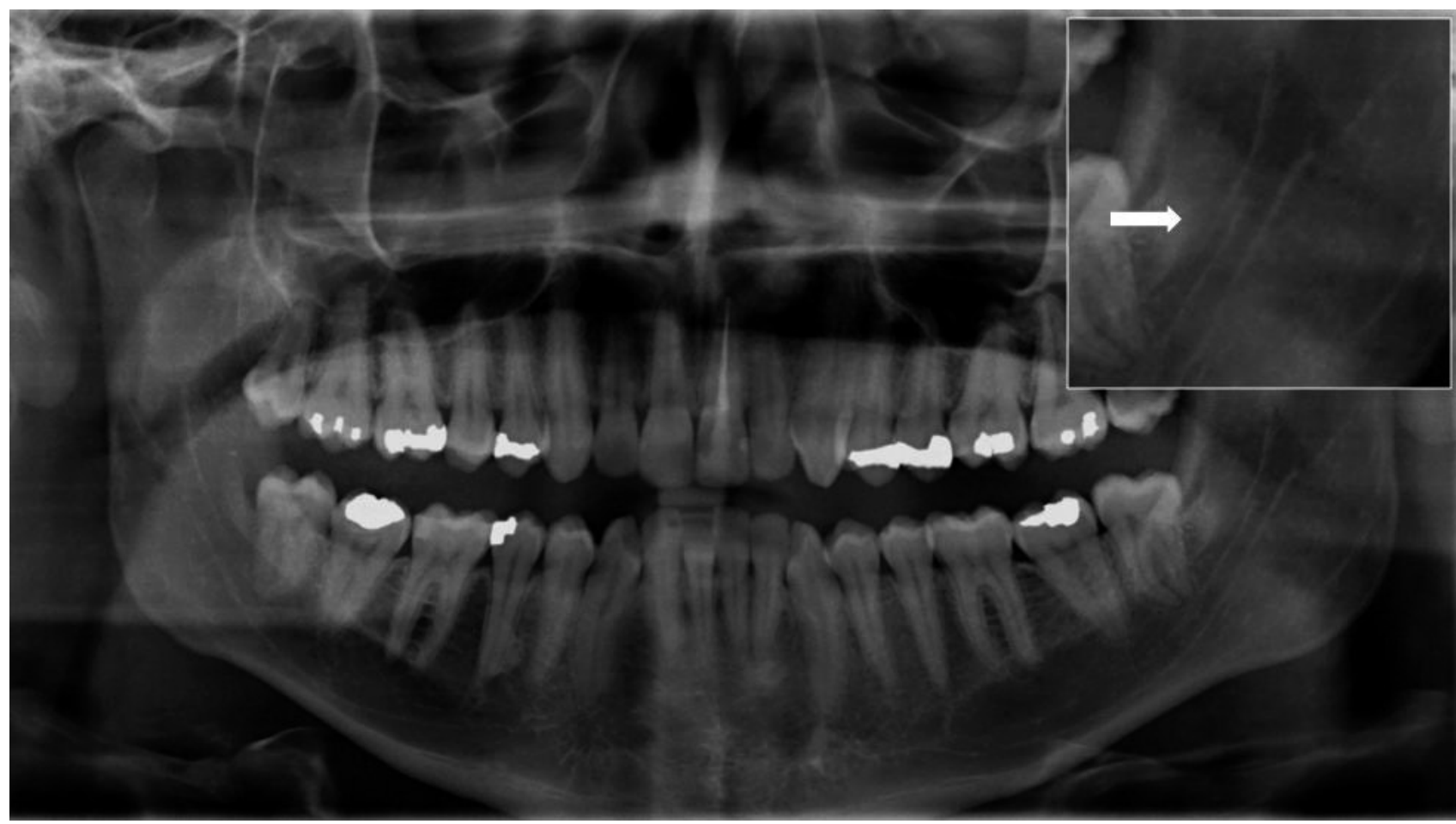

Fig. 3. The zoom in the upper right marked with the arrow corresponds to an image of the loss of continuity of the upper cortex on the mandibular canal.

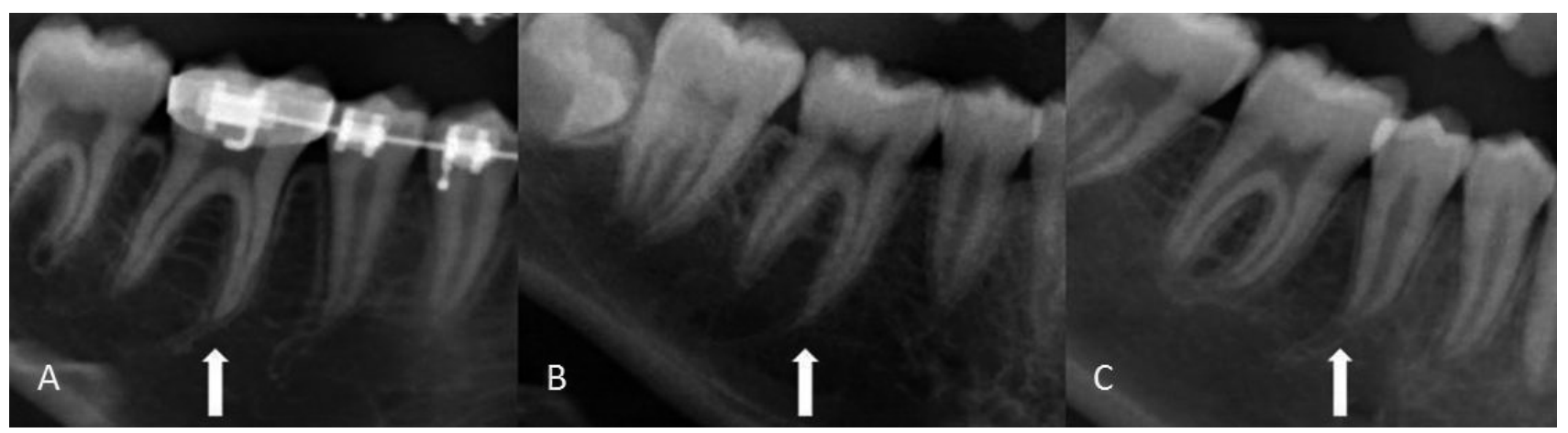

Fig. 4. The figures $A$ and $B$ show the Emergent conduits from the mandibular canal to the apex of the first molar (46 tooth), the figure $\mathrm{C}$ shows the conduct that goes to the apex of the 45 tooth.

On the other hand, during the observations it was noted that in 28 cases $(4 \% n=700)$, there were small conduits (Fig. 4) that emerge from the mandibular canal directly toward the apexes of molars, and in some cases premolars. The average age of these cases was 18.6 years (with a median age of 17 years, standard diversion of 5.33 years). This could correspond to a direct innervations and vascularization that requires in-depth study of the clinical as well as anatomopathological form, for the possibility of nerve damage or risk of hemorrhage in cases of dental extractions. The study realized by Sato et al. reinforces the idea of possible complications during routine root canal treatments.

During observation of an X-ray image in order to evaluate the presence or absence of some type of bifurcation in the mandibular canal, all of the anatomical relations (oblique line, mylohyoid line, mandibular bone depressions, and mylohyoid canal) must be taken into consideration in order to avoid false positives, as in the case of the mylohyoid canal or the mylohyoid conduit. In those cases where the mylohyoid canal enters the thickness of the osseous tissue the image 


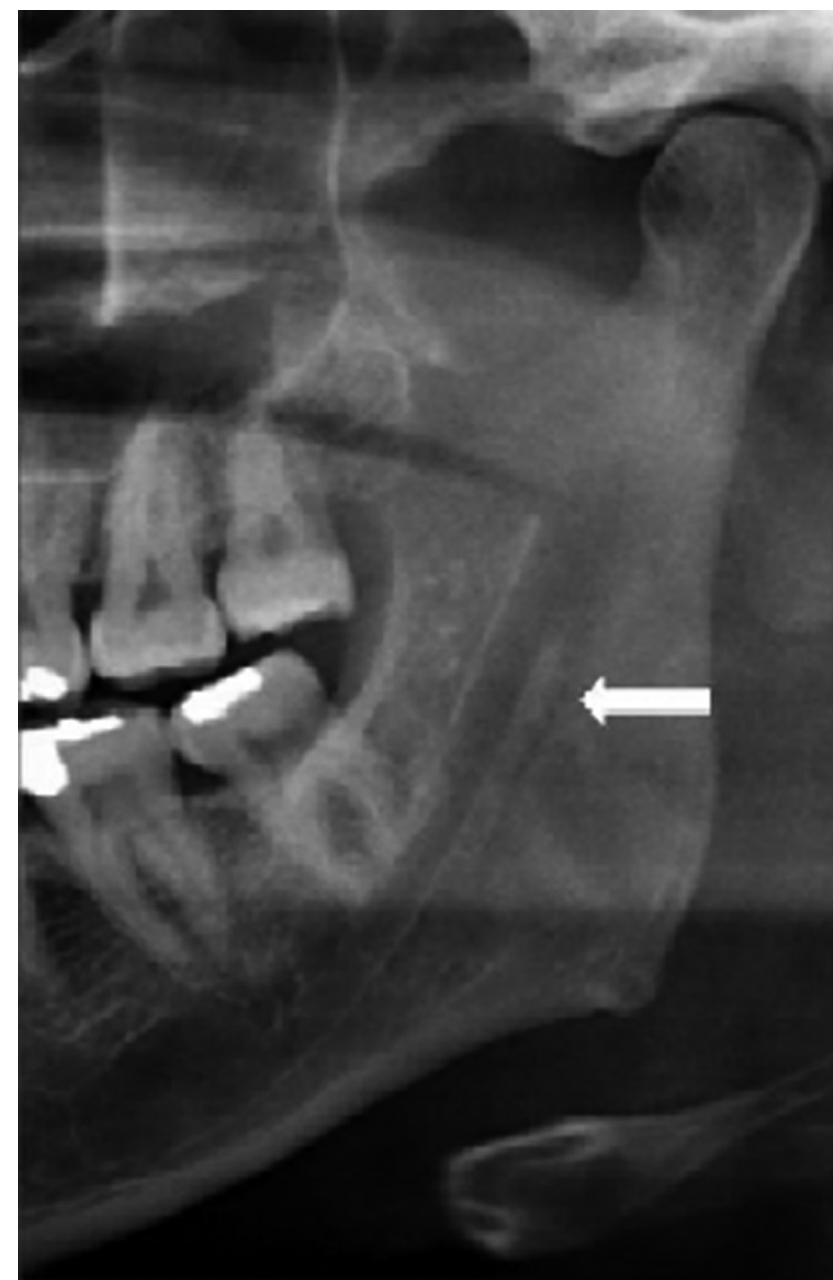

Fig. 5. The arrow indicates de radiolucid band that corresponds to the Mylohyoid canal of a female patient.

delivered by the mylohyoid canal corresponds to a radiolucid band of minor caliber as the mandibular canal, located in its origin at the same level of the mandibular foramen, toward the area immediately below the pertaining mandibular canal (5).

A correlation becomes necessary, between panoramic X-ray images observed and possible estimates in CT scans, provided that bifurcations of the mandibular canal could exist. These images may not be observed in panoramic X-ray images due to absorption and projection phenomena, as well as the possible minor caliber of the bifurcations with regard to spatial disposition, in cranial - caudal direction, as well as in bucco - lingual direction.

This information could relate to the study by Amorim et al. (2008) where the sensibility and specificity of the panoramic X-ray image was established, to predict possible nerve damage during the extraction of third molars. In that study a sensibility of $66 \%$ and a specificity of $39 \%$ was found, which is not sufficient to use in panoramic X-ray photography to predict possible damage to the alveolar lower nerve. Therefore, it could be of interest to conduct an anatomopathological study such as magnetic resonance analysis in order to explain the content of these nerve or vascular bifurcations.

SCHILLING, L. J. A.; SCHILLING, Q. A. \& SAN PEDRO, V. J. Prevalencia de las bifurcaciones del canal mandibular, análisis en Radiografias Panoramicas Digitales. Int. J. Odontostomat., 4(3):207-213, 2010.

RESUMEN: El aumento de los procedimientos quirúrgicos realizados en la región mandibular requiere dar una nueva mirada a los reparos anatómicos como el canal mandibular y su aspecto imagenológico. El presente estudio tuvo como propósito determinar la prevalencia de las alteraciones de número del canal mandibular en imágenes panorámicas del período de marzo a diciembre de 2008, obtenidas de pacientes de un centro radiológico privado de la región del Maule. Para el efecto se analizaron 350 radiografías panorámicas digitales, examinándolas por hemiarcada $(n=700)$ y cuantificando las alteraciones de número del canal mandibular. Se encontraron 35 casos de bifurcaciones de canal mandibular correspondientes al $5 \%$ de la muestra en estudio. Los datos obtenidos indican una prevalencia mayor a la descrita por la literatura, lo que refuerza la necesidad de un estudio acabado de las imágenes radiográficas del canal mandibular, considerando el difícil manejo de una complicación quirúrgica sobre esta estructura anatómica.

PALABRAS CLAVE: canal mandibular, radiografía panorámica, nervio alveolar inferior.

\section{REFERENCES}

Amorim, A. C.; Cavalcanti, B.; Dias de Oliveira, E.; Caldas, A. \& Cavalcante, I. Sensitivity and specificity of pantomography to predict inferior alveolar nerve damage during extraction of impacted lower third molars. J. Oral Maxillofac. Surg., 66:256-9, 2008.

Claeys, V. \& Wackens, G. Bific mandibular canal: Literature review and case report. Dentomaxillofacial Radiology, 34:55-58, 2005.

Carter, R. B. \& Keen, E. N. The intramandibular course of the inferior alveolar nerve. J. Anat.,108(3):43340, 1971. 
Chávez-Lomeli, M. E.; Mansilla Lory, J.; Pompa, J. A. \& Kjaer, I. The human mandibular canal arises from three separate canals innervating different tooth groups. J. Dent. Res., 75(8):1540-4, 1996.

Denissen, H. W.; Veldhuis, H. A. \& van Faassen, F. Implant placement in the atrophic mandible: an anatomic study. J. Prosthet. Dent., 52:260-3, 1984.

Farman, A. G.; Nortjé, C. J.\& Grotepass, F. W. Pathological conditions of the mandible: their effect on the radiographic appearance of the inferior dental (mandibular) canal. Br. J. Oral Surg., 15:64-74, 1977.

Flygare, L. \& Öhman, A. Preoperative imaging procedures for lower wisdom teeth removal. Clin. Oral Invest., 12:291-302, 2008.

Gowgiel, J. M. The position and course of the mandibular canal. J. Oral Implantol., 18:383-5, 1992.

Kjaer, I. Prenatal development of the maxillary primary incisors related to maturation of the surrounding bone and to postnatal eruption. In: The biological mechanisms of tooth eruption and root resorption. Davidovitch D, editor. Birmingham, AL: EBSCO Media, 1988. pp. 233-236.

Langlais, R. P.; Broodus, R. \& Glass, B. J. Bifid mandibular canals in panoramic radiographs. J. Am. Dent. Assoc., 110:923-6, 1985.

Lew, K. \& Townsen G. Failure to obtain adequate anaesthesia associated with a bifid mandibular canal: a case report. Aust. Dent. J., 51(1):86-90, 2006.

Olivier, E. Le canal dentaire inférieur ET son nerf chez l'adulte. Annls. Anat. Path. Anat. Norm. méd.-chir., 4:975-87, 1927.

Polland, K.; Munro, S.; Reford, G.; Lockhart, A.; Logan, G.; Brocklebank, L. \& McDonald, S. The mandibular canal of the edentulous jaw. Clin. Anat., 14:44552, 2001.

Sanchis, J. M.; Peñarrocha, M. \& Soler, F. Bifid mandibular canal. J. Oral Maxillofac. Surg., 61:4224, 2003.

Sato, I.; Ueno, R.; Kawai, T. \& Yosue, T. Rare courses of the mandibular canal in the molar regions of the human mandible: a cadaveric study. Okajimas Folia Anat. Jpn., 82(3):95-102, 2005.

Tsuji, T.; Muto, T.; Kawakami, J. \& Takeda, S. Computer tomographic analysis of the position and course of the mandibular canal: relevance to the sagittal split ramus osteotomy. Int. J. Oral Maxillofac. Surg., 34:243-46, 2005.

Wadu, G.; Penhall, B. \& Townsend, G. C. Morphological variability of the human inferior alveolar nerve. Clin. Anat., 10:82-7, 1997.

Worth, H. M. Normal Radiographic appearance of the teeth and jaws and variations within the normal. In Principles and Practice of Oral Radiologic Interpretation. Chicago: Year Book Medical Publishers, $15-79,1963$.

Correspondence to:

Juan Andrés Schilling Lara

Departamento de Estomatología

Escuela de Odontología

Facultad de Ciencias de la Salud

Avenida Lircay s/n, Universidad de Talca

CHILE

Phone: 56-71-200476

Email:jschilling@utalca.cl

Received: 24-08-2010

Accepted: 22-09-2010 
